\title{
Research on the Value of Sports Performance Art Education in the Diverse Sports Culture in Chinese Colleges and Universities
}

\author{
Bin Chen \\ School of physical and military education, Jingdezhen Ceramic Institute, Jingdezhen, 333403, China
}

Keywords: Sports performance art, Physical education, Diverse sports culture, Value.

\begin{abstract}
Sports performance art is a major that has been added in the past few years in China's ordinary universities and sports colleges in line with the current social and market demand for sports development. Sports performances are used as artistic materials to express sports culture phenomena. Sports performance art education is an important way to implement college students' physical education and artistic quality education. It is of great value in the construction of diverse sports culture in China's colleges and universities, which is explained in this paper.
\end{abstract}

\section{Introduction}

In the construction of college campus culture, the building of sports culture is of great significance. Especially in the new era, based on the needs of society and market, the development of sports culture tends to be diversified. Broadly speaking, college sports culture is the sum of material and spirit created by universities in the process of physical education and learning. In a narrow sense, college sports culture is formed in the process of college development, reflecting the value of school groups. The orientation, lifestyle, behavioral norms and ways of thinking are different from the spiritual atmosphere and group consciousness of other social groups. In view of this, strengthening the sports performance art education and sports culture construction in universities plays an important role in promoting the quality education and spiritual civilization construction of universities, seizing the ideological and political education positions, and creating a good learning atmosphere. In this paper, the author combines his own work experience, using logic analysis and literature review methods to analyze the concept and function of college sports culture and the value of sports performance art education in the diverse sports culture of universities in China, in order to provide a certain reference for the sports cultural construction in universities.

\section{Background of Sports Performing Arts}

In recent years, China's social economy has developed rapidly, and people's material living standards have also been greatly improved at the same time. In this context, people's demand for fitness and cultural life has gradually increased, and the market demand for professionals and the demand for talents have also undergone major changes. Combined with the strategic deployment of China's education industry -- development of education first and construction of a strong country of human resources -- the talent cultivation industry is facing a greater challenge, advancing with the times. Based on the demand of sports professionals in the society and the market, the sports performance art has gradually received attention, and it has quickly become one of the hot spots in the job market in China. However, in view of the current situation of professional talents training, due to the short period of professional development, lack of corresponding experience, and insufficient research, the supply-demand ratio of sports performing arts professionals still has some differences, and the quality of talents needs further Upgrade. In view of this, strengthening the sports performance art education in universities and cultivating professional talents that meet the needs of society and the market is one of the problems that universities need to solve urgently in physical education. 


\section{The Concept of Sports Culture and its Composition}

\subsection{The connotation of modern sports culture}

With regard to the concept of modern sports culture, the definition in Sports Vocabulary is as follows: "Sports culture is an integral part of general culture. It combines various categories and laws that use physical exercise to improve people's biological and spiritual potential, systems and physical facilities." From the perspective of the development of sports culture, it is an important part of human culture and develops in parallel with human society. It is generally believed that sports culture is a special cultural phenomenon exhibited by all sports life and sports phenomena, seeking the healthy development of body and mind through means of education, entertainment and competition for people in the process of sports time. It is a culture of athletic attributes exhibited by changes in skills and body shape. For college sports culture, it is a unique form of campus culture created by the interaction of various sports activities in the teaching environment of universities, such as sports facilities on campus, sports competitions or sports activities organized regularly, and activities displayed in the activities. Sports performances, as well as the sportsmanship demonstrated by students. Like other cultures, sports culture has the characteristics of advancing with the times, and can also be understood as the development and change of sports culture. In the new era, the diversity of sports culture is a more important development trend.

\subsection{The composition of modern sports culture}

In view of the hierarchical structure of modern sports culture, there are mainly three levels of theory and four levels of theory. In the three-level theory, culture is divided into outer, middle and inner layers. The outer layer is a physical entity with human creation color, the middle layer is a theoretical and organizational system related to the law of social development, and the inner layer is a cultural psychological state. In the four-level theory, culture is considered to include material culture level, spiritual culture level, social relationship system level, and art culture level. As far as sports culture is concerned, if it is divided into three levels, the surface layer is the material form, such as the form of sports, the venues, equipment, equipment and clothing used in sports; the middle layer is the system of sports culture, such as physical education and sports. The system and organization of training, the social organization of sports culture, etc.; the deeper is the concept of sports culture, such as the psychology, values, sports concept and methodology of sports culture. In the construction of sports culture in universities, the spiritual level dominates and determines the goal of sports culture; the system and method are the concrete manifestation of sports consciousness; the material level is the objective material guarantee and development foundation of sports culture.

\section{The Status Quo of Sports Performing Arts Major}

With the continuous improvement of the sports science system, the fusion form of physical education and art education appears, that is, sports performance art. At present, the construction and development of sports performance art has received extensive attention from the society. As far as the opening of this major is concerned in China's universities, there are more colleges offering sports performing arts, and the number of enrollment per year is increasing year by year. However, in terms of the quality and quantity of talent training, it is still difficult to meet the needs of society and the market.

In view of the teaching and training objectives of the sports performance profession, some people believe that the goal of talent training should be scientifically positioned and adjusted accordingly according to the specific conditions of implementation. Relevant literature points out that the training of talents in sports performing arts is mainly divided into three types: applied, compound and advanced. All universities should fully grasp the needs of the market in the new era, combine their own actual conditions, scientifically position the types of talents, carry out key personnel training, and highlight professional characteristics. 


\subsection{The Value of Sports Performance Art Education in Diverse Sports Cultures of Universities}

Sports performance art is the carrier of humanistic quality education, which plays an important role in improving the cultural level, social ability, aesthetic ability and artistic accomplishment of college students. The establishment of sports performance art in universities is not only a concrete manifestation of the implementation of the people-oriented teaching philosophy, but also an important measure to cultivate talents that meet the needs of social development and market needs. Based on scientific and reasonable sports performance art teaching, it can help students shape body shape, good psychological quality, and stimulate students' creative thinking ability.

\subsection{Promote the Self-development of Students}

The main part of the sports performance is the movement of the body. During the training, the students need to continuously complete a set of sports composed of various sports types, such as jumping, gymnastics, and sports skills. In general, the whole set of actions consists of actions with different levels of difficulty, which can effectively exercise the endurance of the students. Therefore, the teaching of sports performing arts can better exercise students' athletic ability and physical quality, thus affecting their physical form and physical skills. In the teaching process, the student's gender, age and physical condition should be combined to determine the exercise load, and then the teaching should be arranged in a targeted manner to guide the students to complete the corresponding training tasks to promote the development of students' physical and mental health. In addition, in the organization process of college sports activities, there is always a figure of sports performance art, which provides a certain exercise platform for students. With the help of sports performances, the enthusiasm of teachers and students can be fully mobilized, and students' social skills can be improved to a certain extent at the same time, laying an important foundation for their career development.

In college education, cultivating students' aesthetic ability and improving their artistic accomplishment will have a great impact on their future development. Different from traditional physical education, sports performance art teaching is an effective integration of physical education and art teaching. In addition to the physical quality, sports skills and body shape of students, it is also necessary to pay attention to artistic effects and costume matching, audience effects and overall effects. For the art performance projects, the decorative beauty, the beauty of the action and the beauty of the mood, combined with the unique atmosphere created by music and lighting, have created more favorable conditions for the improvement of students' aesthetic ability. In the teaching activities, based on the corresponding theoretical teaching and practical guidance, students can enjoy the beauty enjoyment, such as the harmonious beauty of music and action, the physical beauty of skill movements, and the beauty of costumes. Using the corresponding teaching methods to enhance students' aesthetic taste will greatly affect the future development of students and their comprehensive ability.

\subsection{Promote the Development of Campus Sports Culture}

Based on the new development of college sports with knowledge education, emotional education, personality education and innovative education, the sports culture of universities will form a flexible and diversified pattern. Therefore, students of different levels, different needs and different personalities are provided with different training programs, and sports performance art education will realize the flexible and diversified development of students' commonality and individuality, so as to meet the physical education needs, quality education requirements and the need for future development of college students. In the sports performance art education, combining the training program to set the course objectives, highlighting the students' main role in theoretical study and training practice, will be conducive to the cultivation of students' expertise and sports hobbies, and even the cultivation of sportsmanship.

Under the background of diverse culture, the development of campus sports has played a complementary role in the promotion of school physical education, and has also greatly enriched the 
campus cultural life. Relevant surveys show that in the management of sports culture construction in universities, because there is no adequate attention to the cultivation of students' sports spirit, lack of necessary support, and the construction of campus sports culture has no clear direction, leading to campus sports culture. The construction situation is not optimistic. In recent years, universities have set up sports performance art, and the role of sports culture in the construction of college campus culture has gradually received attention. On this basis, based on the actual situation of the university itself, breaking through the traditional teaching methods, attaching importance to the propaganda of sports culture, and strengthening the construction of relevant infrastructure, can effectively promote the construction of diverse sports culture and promote the healthy development of college campus culture.

\subsection{Promote the construction of campus spiritual civilization}

College campus sports culture is an important part of campus culture construction, and it plays an important role in promoting good school spirit and improving spiritual civilization. Among the many activities on campus, sports and competitions are popular among students. The sports performances at the opening ceremony can increase the atmosphere of the competition, and in the major events such as the opening ceremony and the celebration, there are also sports performances. Therefore, the teaching of sports performance art plays a vital role in the construction and development of campus sports culture. Based on the wonderful sports performances, it not only can show the youth and vitality of college students in the new era, but also highlight the atmosphere of the activities, and also stimulate the interest of other students and actively participate in the activities. In the process of sports performance, it effectively mobilized and enhanced the enthusiasm and initiative of teachers and students to participate in sports activities, promoted the benign development between teachers and students, and also enhanced the friendship between students and students. The construction of culture and even harmonious campus culture also plays a positive role.

\section{Summary}

In the context of multiculturalism, the establishment of sports performance art in universities is not only in line with the needs of the times, but also meets the needs of college students' physical and mental health development. In the construction of multi-disciplinary sports culture in universities, the line of talent training is determined combining the actual situation of universities, and talent training programs are formulated and sports performance art education is implemented based on individual differences of students, which can not only improve students' social ability and aesthetic ability, but also has a positive effect on the development of campus sports culture and the construction of spiritual civilization. In view of this, relevant universities should strengthen the research of sports performing arts teaching on the existing basis, improve the quality of teaching, and create favorable conditions for the development of campus sports culture.

\section{Acknowledgement}

This work was supported by the Scientific research project: Cultural value exploration of sports art projects, Jiangxi Social Science Planning Project (15TYQ03).

\section{References}

[1] Zhou Huaiqiu, Liu Banghua, Tang Jingen. Research on the Development of Sports Culture Diversity in Hunan Province under the Background of Multiculturalism, Sports Science and Technology, 2017, 25(1): 1-3.

[2] Niu Lijun. Innovation of Public Physical Education Teaching Mode in Universities under the Background of Multiculturalism, Journal of Contemporary Sports Science, 2017(31): 132-132.

[3] Wang Long. Research on the Value of Cheerleading in College Sports Culture, Art Science, 2017, 
30(6): 414-414.

--951-- 